\title{
Manufacturers' Optimal Strategy in Supply Chain Financing
}

\author{
Xiuwen Gan \\ College of Economics \& Management, Nanjing Institute of Technology, Nanjing, 211167, China
}

\begin{abstract}
Keywords: supply chain financing; manufacturer; strategy
\end{abstract}
\begin{abstract}
: with rapid development of socialist market economy, market competitions also become increasingly fierce. One of important guarantees for enterprise development is capital. However, in current stage, it is very hard for enterprises to borrow money from banks, especially for small and medium-sized enterprises which are caught in the plight of financing difficulty. Our state adopt encouragement attitude for small and medium-sized enterprises. But banks worry capital recovery problem during providing loans for small and medium-sized enterprises. Therefore, small and medium-sized enterprises must seek other financing approaches in order to develop. Supply chain financing is a good approach. However, supply chain financing can achieve maximization of manufacturers' benefit under certain conditions. This paper mainly discusses manufacturers' optimal strategy in supply chain financing to provide reference for enterprise financing and promote enterprise development.

In most cases, small and medium-sized enterprises cannot gain banks loan, because they lack assets guarantee. The emergence of supply chain financing can effectively solve this plight. When enterprises conduct supply chain financing, supply chain partners can provide guarantee for enterprises and the enterprises can apply for loans from banks. This solves financing difficulty of small and medium-sized enterprises. In recent years, many Chinese commercial banks have carried out supply chain financing services. The whole supply chain financing system contains manufactures and retailers. Only when retailers meet manufacturers' financing conditions can manufacturers provide financing guarantee for them.
\end{abstract}

\section{Overview of supply chain financing}

Supply chain is an integral structure constructed through connection. It consists of manufacturers, suppliers, retailers and consumers etc. The whole supply chain includes core enterprises (i.e. enterprises with strong comprehensive strength and large scale), small and medium-sized enterprises. The bank as a core part of supply chain financing is the key of connecting core enterprises, small and medium-sized enterprises. Banks connect each enterprise in the supply chain into an integral whole, carry out collective credit extension, formulate rational financing schemes according to industrial characteristics and chain relations of goods transactions and guarantee integrated management of capital, logistics and various kinds of information. To promote flexible capital turnover for small and medium-sized enterprises is also an objective of supply chain financing. To fulfill financing, small and medium-sized enterprises mainly depend on good credit standing of core enterprises in supply chain financing so that core enterprises can provide guarantee for small and medium-sized enterprises. This is beneficial to financing of small and medium-sized enterprises.

\section{Construction of supply chain financing model}

(I) Hypothesis of supply chain financing

Supply chain mainly includes manufacturers, suppliers, retailers and consumers etc. Manufacturers are in the dominant position in the whole supply chain. Generally, we suppose production cost of goods is $\mathrm{C}$ and $\mathrm{P}$ is the retail price $(\mathrm{P}>\mathrm{C})$. In other words, retail price must be greater than the production cost. $\mathrm{X}$ is the market demand. The value range of $\mathrm{X}$ is any value in $0-\infty$.

If retailers have no fixed assets, but only have cash, where the quantity of cash is $\eta(\eta>0)$, and 
the cash owned by retailers does not own debt repayment capacity, retailers have to go bankrupt. If retailers go bankrupt, the creditors will suffer losses. When the quantity of cash does not comply with retailers' demand, retailers need financing. Because the scale of retailers is small with low credit standing, they need to depend on supply chain for financing. Manufacturers will provide guarantee for retailers so that they can apply for bank loans.

When the whole sales process is finished, there are no overstocked imperfect goods. Enterprise credit is not influenced due to insufficient supply of goods. Risk bearing of manufacturers ad retailers is in the neutral position. The basis for financing decision making is expected profit available. Generally, manufacturers' expected profit must be more than 0. Only when this condition is met can retailers participate in transactions, but one case is excluded, i.e. when the profit is less than 0. But, retailers still participate. This has direct relationship with creation of popularity by retailers.

(II) Calculation method for expected profit

If the retailers do not get involved in financing, such situation should be labeled with 0 . In case of supply chain financing, such situation should be labeled with 1 . Without financing, computational formulas of expected profits of manufacturers and retailers are as follows:

$$
\begin{aligned}
\Pi_{\mathrm{m}, 0} & =(\omega-\mathrm{C}) \mathrm{q} \\
\pi_{\mathrm{r}, \mathrm{o}} & =(\mathrm{P}-\omega) \mathrm{q}-\mathrm{P} \int_{0}^{q} \mathrm{~F}(\mathrm{x}) \mathrm{dx}
\end{aligned}
$$

The expected value of surplus goods in the end of sales is expressed with the following formula:

$$
\int_{0}^{q} \mathrm{~F}(\mathrm{x}) \mathrm{dx}=\int_{0}^{q}(\mathrm{q}-\mathrm{x}) \mathrm{f}(\mathrm{x}) \mathrm{dx}
$$

Under the condition of supply chain financing, $\omega q-\eta$ means retailers loan fund amount and $\gamma$ is loan interest rate $(\gamma>0)$. When the loan expires, the retailers' repayment amount is calculated as follows: $(1+\gamma)(\omega q-\eta)$. Market demand is $\mathrm{X}$. Market demand evaluation standard is $\theta$. The computational formula is:

$$
\theta=\frac{(1+\gamma)(\omega q-\eta)}{P}
$$

When $\mathrm{X}>\theta$, this means retailers own repayment capacity. When retailers apply supply chain financing, the condition is $0<\theta<\mathrm{q}$. When $\mathrm{X}<0$, this means retailers do not own repayment capacity. This will result in bankruptcy. At this moment, the loan amount will be undertaken by manufacturers. If manufacturers on repayment capacity, during studying ordering decision under newsvendor model, if the cycle is very short, the interest from the sales funds in sales process can be basically neglected. Meanwhile, manufacturers' fund income resulting from loan in this cycle can also be neglected. Therefore, under supply chain financing, computational formulas of expected profits of manufacturers and retailers are:

$$
\begin{aligned}
& \pi_{\mathrm{m}, 1}=(\omega-C) \mathrm{q}-\mathrm{p} \int_{0}^{\theta} \mathrm{F}(\mathrm{x}) \mathrm{dx} \\
& \pi_{\gamma, 1}=(\mathrm{p}-\omega) \mathrm{q}-\gamma(\omega \mathrm{q}-\eta)-\mathrm{p} \int_{\theta}^{q} \mathrm{~F}(\mathrm{x}) \mathrm{dx}
\end{aligned}
$$

In the computational formula of retailers' expected profit, $\gamma(\omega q-\eta)$ refers to loan interest expended. In the whole supply chain financing, manufacturers as the guarantors will undertake responsibility for possible unmarketable goods. In the computational formula of manufacturers'

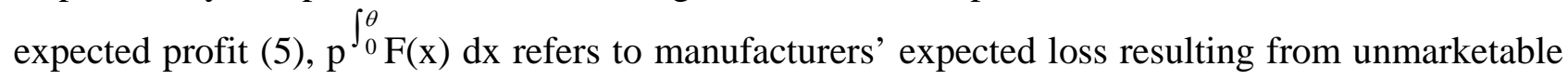
goods. If $\theta=0$, the computational formulas (5) and (6) can be transformed into (1) and (2).

(III) Computing method of order quantity

Order quantity aims at retailers. When retailers have sufficient funds, supposing $\omega$ is wholesale price, the optimal order quantity $\mathrm{q}^{*} \gamma, 0$ of retailers can be directly deduced according to 
Formula (2). The computational formula is:

$$
\mathrm{p} \bar{F}\left(\mathrm{q}^{*}, 0\right)=\omega
$$

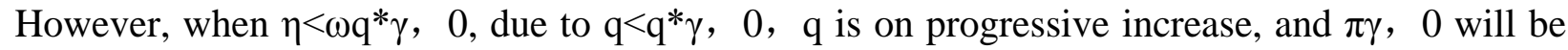
also on progressive increase. This means retailers funds will be used out. If retailers do not choose financing at this moment, order quantity is expressed with ${ }^{\Delta}{ }_{\gamma, 0}$. The computational formula is:

$$
q_{\gamma, 0}^{\Delta}=\frac{\eta}{\omega}
$$

When retailers choose supply chain financing, if $\omega$ is published, order quantity will be confirmed. If retailers choose supply chain financing, and there is still balance after retailers' all funds are used to pay off the loans from manufacturers, IFR is set to demand distribution and $\omega$ is set to wholesale price. Retailers' capital is expressed with $\eta$, while $\gamma$ refers to financing interest rate. Thus, the formula of order quantity is:

$$
\mathrm{q}=\left\{\begin{array}{c}
q^{*} \gamma, 0, \text { 当 } \eta \geq \omega q^{*} \gamma, 0 \\
\Delta \\
q_{\gamma, 0},{ }^{\text {当 } \omega q_{\gamma, 1}^{0} \leq \mu\left\langle\omega q_{\gamma, 0}^{*}\right.} \\
q_{\gamma, 1}^{*}, \text { 当 } \eta\left\langle\omega q_{\gamma, 1}^{0}\right.
\end{array}\right.
$$

The following two formulas are deduced:

$$
\begin{aligned}
& \mathrm{p} \bar{F}\left(\mathrm{q}_{\gamma, 1}^{*}\right)=(1+\gamma) \omega \bar{F}\left(\theta\left(\mathrm{q}_{\gamma, 1}^{*}\right)\right) \\
& \mathrm{p} \bar{F}\left(\mathrm{q}_{\gamma, 1}^{0}\right)=(1+\gamma) \omega
\end{aligned}
$$

\section{Manufacturers' optimal strategy in supply chain financing}

Manufacturers' optimal strategy is formulated according to the order quantity.

(I) Confirmation of retailers' order quantity range under supply chain financing

IFR reserves as demand distribution. If $\mathrm{q}=\mathrm{q}^{*} \gamma, 1, \omega \mathrm{q}$ is the order amount. It is a unimodal

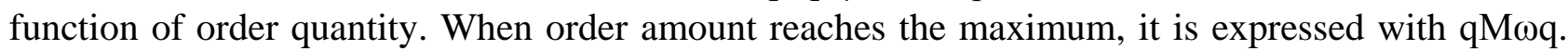
Then, the following formula is gained:

$\mathrm{qM} \omega \mathrm{qf}(\mathrm{qM} \omega \mathrm{q}) / \bar{F}(\mathrm{qM} \omega \mathrm{q})=1$

In combination of (10), the following formula can be deduced:

$\mathrm{D} \omega / \mathrm{dq}=(1+\gamma) 2(\omega 2 / \mathrm{p}) \mathrm{f}(\theta)-\mathrm{pf}(\mathrm{q}) /(1+\gamma) \bar{F}(\theta)-(1+\gamma) 2(\omega 2 / \mathrm{p}) \mathrm{qf}(\theta)$

The extreme value of order mount is

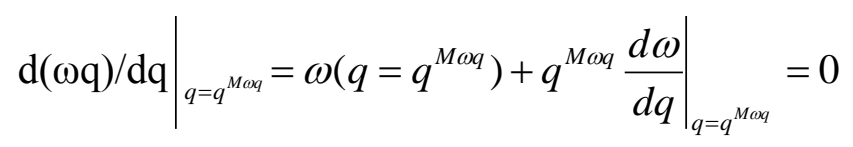

According to (12), (13) and (14), 912) is gained through substituting (13) into (14). IFR has a sole solution in (12). Thus, the extreme value of order amount is also sole. This valley is the maximum value, which is easily known. Similarly, IFR serves as demand distribution. When retailers conduct supply chain financing, $\mathrm{q}^{*} \gamma, 1$ is the optimal order quantity. $\omega$ is its decreasing function. When manufacturers want the retailers to carry out financing, manufacturers should confirm the wholesale price and then retailers can have basis. The precondition for manufacturers' decision is that $\mathrm{q}^{*} \gamma, 1 \in(\mathrm{qA}, \mathrm{qM} \omega \mathrm{q})$.

(II) Manufacturers’ strategy when retailers choose financing 
If retailers choose financing (i.e. $\mathrm{q}=\mathrm{q}^{*} \gamma, 1$ ), the following formula can be gained according to Formula (5):

$$
\mathrm{d} \pi \mathrm{m}, 1 / \mathrm{dq}=[\mathrm{q}-(1+\gamma) \mathrm{qF}(\theta)] \mathrm{d} \omega / \mathrm{dq}-(1+\gamma) \omega \mathrm{F}(\theta)+\omega-\mathrm{C}
$$

Formula (13) is substituted into Formula (15) and combines with (10). Then, the following formula id gained:

$$
\mathrm{d} \pi_{\mathrm{m}, 1} / \mathrm{dq}=-\mathrm{C}+\omega[1-(1+\gamma) \mathrm{F}(\theta)] \times \frac{1-q f(q) / \overline{\mathrm{F}}(q)}{1-[(1+\gamma) \omega / p] q f(\theta) / \bar{F}(\theta)}
$$

It can be seen form the above two formulas that when retailers choose financing, $\pi \mathrm{m}, 1$ changes with changes of q. The following proposition is based on IFR. Demand distribution failure rate further forms convex function. Through demonstration, it is know that general demand distribution is consistent with this condition.

proposition: $\mathrm{f}(\mathrm{x}) / \bar{F}(\mathrm{X})$ is failure rate of demand distribution, and serves as increasing convex $\lim _{4 \rightarrow A}$

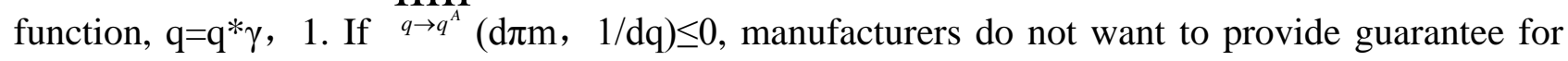
retailers so that retailers cannot conduct financing. If $\lim _{q \rightarrow q^{A}}(\mathrm{~d} \pi \mathrm{m}, 1 / \mathrm{dq})>0$, manufacturers may provide guarantee for retailers so that retailers can conduct financing. Meanwhile, $\pi \mathrm{m}, 1$ gains the optimal order quantity, $\mathrm{q}^{*} \gamma, 1 \in(\mathrm{qA}, \mathrm{qM} \omega \mathrm{q})$. Therefore, the optimal order quantity and wholesale price can be confirmed as follows:

$$
\mathrm{C} / \omega[1-(1+\gamma) \mathrm{F}(\theta)]=1-\frac{q f(q)}{\bar{F}(q)} / 1-\frac{(1+\gamma) \omega q f(\theta)}{p \bar{F}(\theta)}
$$

Through demonstration, this proposition is totally established. Meanwhile, it can be seen form this proposition that if manufacturers are willing to help retailers and provide guarantee for them, the interval of $\mathrm{q}^{*} 1$ is $(\mathrm{qA}, \mathrm{qM} \omega \mathrm{q})$, while the precondition in which manufacturers hope retailers carry out financing is that $\mathrm{q}=\mathrm{q}^{*} \gamma, 1$.

\section{Calculation examples}

If $[0,1]$ is demand distribution, $\mathrm{f}(\mathrm{x})=1$, marginal cost of production $\mathrm{C}$ is $0 . \mathrm{P}$ is retail price and is set to 25. The capital which the retailer originally own is $\eta$ (set to 4). Loan interest rate is $\gamma$ (set to 25). When retailers do not carry out financing, $\mathrm{q}^{*} 0$ is 0.2 ; $\omega^{*} 0$ is 20 ; qA is 0.214 ; $\mathrm{q}^{*} 1$ is 0.35 ; $\omega^{*} 1$ is 16.89 .

It is thus known that the manufacturer's financing scheme is optimal when the value is 2.30 . Without financing, there will be large losses. In this way, profit growth is about 35\%. The manufacturer may provide guarantee for the retailer. Providing guarantee will also suffer certain loss (about 6\%). The profit offsets the loss. Obviously, the profit is larger than the loss. At this moment, the manufacturer is wiling to provide guarantee for the retailer's financing.

\section{Conclusions}

This paper studies manufacturers' optimal strategy in supply chain financing, and explains how to formulate the optimal scheme during supply chain financing with detailed formulas. Meanwhile this paper provides a reliable computing mode for financing of core enterprises, small and medium-sized enterprises in the supply chain and also supplies reference for banks to work out financing plans. This paper contributes to soling financing difficulty of small and medium-sized enterprises and promotes development of small and medium-sized enterprises. 


\section{Acknowledgments}

This paper is a part of fund program of philosophy and social science in Jiangsu colleges: study on financing optimization and operation management coordination decision in capital constraint supply chain (program No.: 2013SJD630024)

\section{References}

[1] Zhang Benzhao, Yan Liangliang, Analysis of “cooperative innovation” game under perspective of supply chain financing $[\mathrm{J}]$. Journal of Hefei University of Technology (Natural Science), 2014(9).

[2] Zhong Yuanguang, Zhou Yongwu and Li Boxun et al., Study on retailers' order and pricing under supply chain financing mode [J]. Journal of Management Sciences in China, 2011, 14(6).

[3]Ghi-Feng Yen,Kun-Jen Chung,Tzung-Ching Chen et al. The optimal retailer's ordering policies with trade credit financing and limited storage capacity in the supply chain system[J].International Journal of Systems Science: The Theory and Practice of Mathematical Modelling, Simulation, Optimization and Control in Relation to Biological, Economic, Industrial and Transportation Systems,2012,43(10/12).

[4] Dong Tao, Study and realization of supply chain financing services based on core enterprises [J]. Journal of Southwest University for Nationalities (Humanities and Social Science), 2012,33(9).

[5] Zhang Jingfeng, Wang Ping, Study on supply chain financing and its management framework [J]. Journal of Beijing Technology and Business University (Social Sciences), 2013,28(3). 